\section{THE MANUFACTURE OF VARIETIES OF} COMMON SALT.

GREAT interest has been aroused among salt manufacturers by the announcement of the discovery of a new process capable of producing every variety of commercial salt in one plant and with great economy of fuel. The inventor is $\mathrm{Mr}$. James Hodgkinson, of the firm of James Hodgkinson, Ltd., Pendleton, Manchester, makers of mechanical stokers. It is said that the patent rights for America have been sold to an American syndicate for $\mathbf{r}, \infty 00,000 l .$, and to the Canadian Pacific Railway Company for Canada.

Up to the present time, salt has been manufactured by a process scarcely different from that used during the Roman occupation, namely, boiling down the brine in shallow open pans heated by coal fires. It is true that in I839 Reynolds introduced the use of closed pans, in which the steam was passed from the first pan to the others, and a considerable economy in fuel effected, one ton of coal yielding four tons of salt, as against two tons in the case of open pans, which, however, still continued in use.

The chief features in the Hodgkinson process are the introduction of mechanical stokers for the fires, and the working of a plant consisting of seven pans, three closed and four open, heated by one fire. The quality and size of the salt crystals largely depend on the temperature, which can be so regulated in the new process as to produce every kind required.

The first pan is covered, and produces, by crystallisation alone, a table salt so fine that no grinding is required. From this pan proceed waste gases, which pass underneath and heat all the remaining pans, while the steam passes over to the succeeding pans and assists the precipitation of the salt. The second and third pans are also covered, and produce a slightly coarser variety, known as " dairy" salt. In the succeeding pans, all of which are open, the gases are at a lower temperature, and coarser salt in larger crystals is obtained. This is known as "fishery" salt, and is used in fish-curing. It should be added that there is an automatic flow of brine into the pans, and an automatic discharge of the salt produced.

The process, first successfully tried at Northwich, then extended to Port Sunlight and St. Helens, has resulted in such complete consumption of smoke that several large chimneys have been dispensed with. The success of the process must be assured if the hopes of the inventor are realised in practice. He claims that four or five times as much salt can be produced in a given time as compared with the old process, and that three tons of coal will be saved out of every four.

ARCHAOLOGICAL RESEARCH IN ARKANSAS. ${ }^{1}$

$M R$. CLARENCE B. MOORE has issued another of his valuable memoirs on the prehistoric pottery of the United States. His last season's field work was on the St. Francis, Little, White, and Black rivers in Arkansas. Like all his other memoirs, this one is illustrated with maps and very numerous beautiful illustrations, many in colours, and all of large size, so that every detail is visible. Mr. Moore is still in the collecting stage of his work; generalisations we may expect at a future time. The principal sites along the St. Francis, although, as a rule, having mounds in connection with them, are in reality great dwelling-sites which have increased in height gradually through long periods of occupancy, and the aborigines, burying where they lived, have formed in course of time great cemeteries, all of which he believes to be pre-Columbian, since no object was found in any way indicating intercourse with Europeans excepting a bone comb, which, "though the shape is undoubtedly copied from a European model, the decoration points to Indian workmanship"; he asserts it is prehistoric.

The St. Francis valley has yielded more examples of its ware than has any equal area in the United States, and has been largely exploited by irresponsible collectors. The earthenware is shell-tempered. Quantity rather than quality seems to have been the aim of its makers, for the

1 Journal of the Academy of Natural Sciences of Philadelphia. 2nd series, vol. xiv., part 2: "Antiquities of the St. Francis, White, and Black Rivers, Arkansas," by C. B. Moore, pp. 255-364 (Philadelphia, 1910).

NO. 2 I.58, VOL. 86$]$ ware is often insufficiently fired, and the vessels are frequently thick and lop-sided. A high polish is almost absent. A very large proportion of the vessels are undecorated or with trivial decoration. Incised decoration is scarcely ever seen, the inferior surface of most of the ware being unsuited to incised decoration of excellent quality, even had it been attempted. Practically none of the vessels obtained by him are of types new to the pottery of the Middle Mississippi valley. The types of pottery have been well described by Prof. W. H. Holmes in his "Aboriginal Pottery of the Eastern United States" (2oth Ann. Rep. Bur. Am. Eth). The most noteworthy find was a ceremonial "spear-head" of sheet-copper. Several vessels in the form of heads with fairly well-modelled faces were obtained, and some in the form of human figures. One burial of a very young infant had near by it a small bowl in which, upright, was a little effigy bottle.

Unlike the St. Francis river sites, which are on high ground, the sites on the White river and its upper reaches, the Black river, are on low, overflow ground, where archæological research is not likely to be rewarded; indeed, with a few trifling exceptions, no aboriginal objects had previously been obtained from this district. With one exception, no site of interest was found along the White river, and but three vessels of earthenware were encountered along the stream. Along the Black river, while some vessels were found, not one was of a character to warrant its transportation home. Although burials were fairly numerous, they were almost invariably unaccompanied by artifacts, a remarkable fact considering the custom of lavishing deposits upon the dead as practised by aborigines of neighbouring regions. The best find was a narrow, well-made ceremonial axe-head of green quartzite, $212 \mathrm{~mm}$. in length.

A. C. Haddon.

THE COEFFICIENT OF SKIN FRICTION IN AIR AT MODERATELY HIGH VELOCITIES.

THE object of this study is to find a coefficient of turbulent friction readily applicable to the design of aërodynamic appliances such as aëroplanes and windmills.

It is assumed throughout that:-

(I) The surfaces on which the friction occurs are of reasonably smooth finish, and present no marked head resistance due to irregularities of surface.

(2) The velocities of the air relative to the surface are well above the critical values at which pure viscous shearing resistance is superseded by the generation of momentum in the contacting film or fluid, so that the skin resistance varies as the square of the velocity.

(3) The length of the surface in the direction of motion bears so small a relation to the dimensions perpendicular thereto that the diminution of the coefficient with the length is inappreciable.

The study is divided into two parts :-

(a) An analysis of the various methods of determining the skin-friction coefficient already known, with a tabular record of the numerical results already attained or thereby deducible, leading up to the most probable value of the said coefficient.

[(b) An experimental study made with the purpose of confirming the accuracy or otherwise of the said probable value. This is now in progress, the apparatus (an epicyclic differential dynamometer) being made. As this will not be ready for some considerable time, it may be useful to publish the comparative analysis beforehand.]

\section{Symbols Employed.}

British engineer's units-Pounds, feet, seconds. Force in Ibs. wt.

$f$. Coefficient of skin friction.

$\mathrm{C}=$ about 0.7 , being the coefficient of normal pressure on unit square surface, with unit velocity, and unit mass of air.

$\rho$. Mass of unit volume of air at normal temperature. About 0.08 pound per cubic foot.

$\mathrm{A}_{1}$. Area subiect to skin friction.

$\mathrm{A}_{2}$. Area of mid-section or normal surface of a dirigible.

$k$ : Ratio of skin friction on a dirigible to normal resistance on an area equal to the cross-section. 
c. Coefficient of oblique air pressure (Lanchester). The value of this depends on the aspect ratio of the surface. From Duchemin's rule for square surfaces it is 2; Eiffe gives a value of 3 ; Lanchester gives hypothetical values between 2 and 3 .

$\xi$. Ratio of skin friction on a double surface to the normal resistance of the plane of the same single-surface area.

$\beta$. Angle of incidence (Radians).

V. Relative velocity of air to surface.

$l$. Length of surface in the direction of flow.

\section{A.}

\section{I.-Frictional Resistance deduced from the Head, or} Total Resistance of Dirigible Balloons.

The resistance of a well-shaped dirigible is, like that of a ship, almost entirely due to skin friction. The aërodynamic resistance of cars, rigging, \&c., is almost negligible in ratio to the skin friction; certainly not exceeding 30 per cent. thereof.

If, then, the area of the skin is $A_{1}$, and that of the maximum cross-section is $A_{2}$, and $k$ is the ratio of the skin friction to the aërodynamic resistance of a normal surface with the same shape as the mid-section, this definition of $k$ may be written :-

$$
\frac{f \mathrm{~A}_{1}}{\mathrm{C}_{\rho \mathrm{A}_{2}}}=k
$$

The coefficient $k$ has been measured for several dirigibles, and forms the basis of this computation.

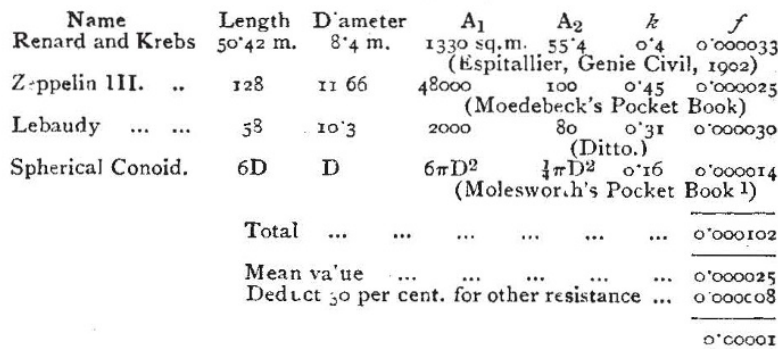

The value 0.000025 , seeing that it certainly includes some aërodynamic resistance due to imperfect form of envelope and the resistance of car and rigging, should be regarded as the absolute maximum.

\section{II.-Frictional Resistance deduced from the Efficiency of a Plane Aërofoil.}

According to Turnbull (Physical Review, March, 1907), the lift-to-drift ratio is a maximum for planes of an aspect ratio of two, when the angle of incidence is $3^{\frac{3}{2}}$ degrees, and it has then a value of 5.1 ( $3 \frac{1}{3}$ degrees $=0.06$ radian)

Employing Lanchester's notation, this ratio (also called by Turnbull the "efficiency")

$$
\begin{gathered}
=\frac{\mathrm{C}_{\rho} \rho \mathrm{AV}^{2} \beta}{\xi \mathrm{C} \rho \mathrm{AV}^{2}+\mathrm{C} c \rho \mathrm{AV}^{2} \beta^{2}} \\
=\frac{c \boldsymbol{\beta}}{\xi+c \boldsymbol{\beta}^{2}}
\end{gathered}
$$

$c$, according to Lanchester (compare Dines, Eiffel, and Rateau), is about 2.5 , so that $\xi=0.020$ for the double surface and $f=\xi \mathrm{C} \rho=0.000032$ for the double surface, or for the single surface 0.000015 .

\section{III.-Frictional Resistance in Air deduced by Comparison with that of Water.}

The investigations of Froude have led to a fairly accurate knowledge of the frictional resistance of water and it has been thought by many that a simple ratio exists between this and that of air in similar circumstances.

Froude's coefficients are between 0.003 and 0.005 , the total resistance varying with a power of the velocity from $\mathrm{I} .83$ to 2.0 when there is considerable turbulence. It is probable that the lower density of air renders it more

1 This result is apparently after Pole's figures, but the resistance seems to have been under.estimated.

NO. 2 I 58 , VOL. 86$]$ easily subject to turbulent conditions, so that there can be little doubt as to the approximate truth of the velocity squared hypothesis.

(a) Assuming that the friction is purely dependent on the density, since the density of water is about 800 times that of air, $f$ may be $=0.004 / 800=0.0000052$.

(b) Assuming that the friction varies as the density, and also as the square root of the kinematic viscosities, an assumption consonant with hydrodynamic theory,

$$
f=\text { sq. root of } 12 \times 0.004 / 800=0.000017 \text {. }
$$

$$
\text { IV.-Zahm's Investigations. }
$$

Prof. Zahm, by experimenting in a wind tunnel on boards, obtained a formula as follows :-

$$
f=0.000008 l^{-0 \cdot 07} \mathrm{~V}^{18 \cdot 5}
$$

for smooth surfaces and no vibration, increasing up to $f=0.0000$ r (total resistance varies with $\mathrm{V}^{2}$ ) for turbulent conditions and buckram-covered surfaces.

\section{V.-Lanchester's Investigations.}

Index of velocity variation $=2$.

Mr. F. W. Lanchester, experimenting with gliding models, and also with an aërodynamic balance (similar to that designed by Ritter von Loessl), obtained various results.

$$
\begin{aligned}
& \text { Nature of surface } \\
& \text { Mica } \quad \ldots \quad \ldots \quad \text { Gliding angle of models } \\
& \text { of variable area ... ... }
\end{aligned}
$$

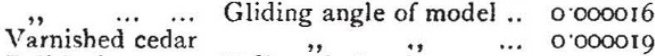

$$
\begin{aligned}
& \text { Polished ", Ballacted aëroplane } \ldots . .0000005 \\
& \text {," " Aërodynamic balance ... } \\
& \text { Glass paper "... , } \\
& \text { 6) } 0.000078
\end{aligned}
$$

Mean value for moderately smooth surfaces 0.000013

$$
\text { VI.-Collected Results. }
$$

I. From the resistance of dirigibles $\ldots .0 .000017$ II. Turnbull's observations $\ldots . \ldots .000015$ III. Hydrodynamic theory and Froude's observations of water $\ldots . \quad \ldots \quad \ldots .000017$

IV. Zahm's observations $\ldots . \ldots \quad \ldots \quad \ldots .000010$

V. Lanchester's observations $\quad \ldots .61 . . .0000013$

$$
\text { General mean } \quad \ldots \quad \ldots \frac{5 \longdiv { 0 . 0 0 0 0 7 2 }}{0.000014}
$$

\section{BIOLOGY OF THE EEL-FISHES, ESPECIALLY} OF THE CONGER.

D CRING the Atlantic and Mediterranean cruises of the Danish research steamer Thor, in the winter of $1908-9$ and summer of 1910 , a very large material has been collected of the larvæ of the eel-fishes (Leptocephali). These belong to at least twelve different forms, and several of them can be referred to their parent species.

The material is specially rich in a few of the forms, and this permits of important conclusions being drawn with regard to the biology of these species. At the same time, it has yielded valuable information regarding the occurrence of the very youngest stages (pre-Leptocephali)information which has long been desired and sought after; and, lastly, it has aided us in the determination of the age of the older Leptocephali, a. question which the hitherto available information has been quite unable to settle.

The species of eel which is of the greatest practical interest in Great Britain is the Conger, and of this we have now a very large and complete material. Several hundred specimens have been taken-in all stages, from a length of only $9 \mathrm{~mm}$. up to ca. $160 \mathrm{~mm}$.

The larvæ are not difficult to determine, in part from the number of myomeres, which in ten specimens $I$ have found to vary between $I_{53}$ and 159 , thus quite the same as in the adult Conger; below $35 \mathrm{~mm}$. the most posterior 